\title{
¿MATEO EVANGELISTA EN MACROBIO, SAT. II 4, 11?
}

\begin{abstract}
It is considered as a very likely hypothesis that Macrobius - an author who, as a rule, ignores Christian people in his work - has read St. Matthew's Gospel, in the Itala version. Echoes of the children's killing by Herod the Great's orders can be traced back.
\end{abstract}

No tenemos datos seguros sobre la vida de Macrobio. Se le considera africano, él mismo nos dice que no es latino: nisi sicubi nos, sub alio ortos caelo, Latinae linguae uena, non adiuuet (Sat. I, praef. 11). Parece que fue funcionario imperial en España hacia finales del siglo IV d. C. y es probable que se convirtiera al cristianismo al fin de su vida (cf. G. Fraile, Historia de la Filosofía, I, Madrid 1976, p. 778).

Es fácil apreciar que Macrobio, aunque puede suponerse que no leyó todos los autores que cita en su obra -posiblemente utilizó comentarios-, no cita todos los que leyó (Séneca, Aulo Gelio y otros). Ya al comienzo de una de sus obras, Sat. I, praef. 4, dice: nec mihi uitio uertas, si res quas ex lectione uaria mutuabor ipsis saepe uerbis quibus ab ipsis auctoribus enarratae sunt explicabo, y en otro pasaje, Sat. I, praef. 6, añade: nos quoque quicquid diuersa lectione quaesiuimus committemus stilo, ut in ordinem eodem digerente coalescant.

¿Podremos afirmar que Macrobio había leído a San Mateo evangelista?

La hipótesis de la lectura de los Evangelios del citado autor se basa en su calidad de compilador y en sus inquietudes religiosas y filosóficas, pero, según puede comprobarse por el pasaje que a continuación se cita, su conocimiento del evangelista Mateo es, más que probable, evidente. 
San Mateo 2, 16

(Vulg.) Tunc Herodes uidens quoniam illusus esset a Magis, iratus est ualde, et mittens occidit omnes pueros qui erant in Bethlehem et in omnibus finibus eius a bimatu et infra secundum tempus quod exquisierat a Magis.

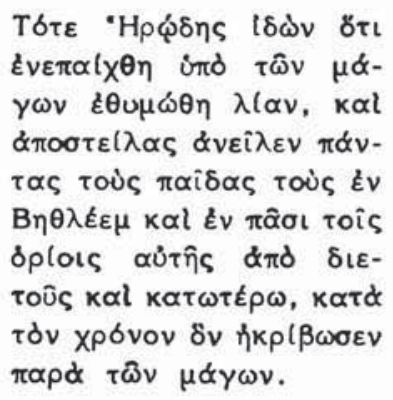

Macrobio, Sat. II 4, 11

Augustus..., cum audisset inter pueros, quos in Syria Herodes rex Iudaeorum intra bimatum iussit interfici, filium quoque eius occisum, ait: 'melius est Herodis porcum esse quam filium'.

¿Traduce Macrobio directamente del griego? ¿Se basa, por el contrario, en alguna versión de la Vetus Latina, la Itala o la Afra, las dos prejeronimianas? Posiblemente la Itala: es una versión que corría por Italia en la época de Macrobio.

Se puede argüir en favor de la primera hipótesis, o sea, de su traducción directa del griego, el hecho de que conocía y escribía la lengua griega (tenemos el testimonio en toda su obra y especialmente en el estudio $\mathrm{De}$ differentiis et societatibus graeci latinique uerbi), pero no me parece esta realidad suficiente razón. También otros autores como Comodiano, Arnobio, etc., lefan griego y leyeron la Afra, y posiblemente también lo hizo Tertuliano, en cuya época circulaba por la Iglesia de Africa la versión Africana de la Vetus Latina, así como San Agustín, que parece dio el nombre a la Itala (cf. De doctrina Christiana II 15, 22: in ipsis autem interpretationibus Itala ceteris praeferatur, nam est uerborum tenacior cum perspicuitate sententiae).

Entre los distintos códices de la Itala, Macrobio podría haber lefdo el siguiente texto:

(Mateo 2, 16)

Tunc Herodes, cum uidisset, quoniam inlusus est magis, indignatus est nimis et misit interfecit omnes pueros, qui fuerunt Bethlem et in omnibus finibus eius, a bimatu et infra, secundum tempus, quot exquisierat a magis.

Ofrece este texto interfecit, forma usada en infinitivo por Macrobio, en vez de occidit que se registra en la Vulgata.

Mateo es el único evangelista que hace referencia a la adoración de los Magos y por tanto a la muerte de los Inocentes por orden de Herodes el Grande, aunque también Lucas habla de la infancia de Jesús de Nazaret. 
Macrobio inserta este hecho en el libro II de las Saturnales, dedicado exclusivamente a relatar anécdotas - dicta - entretenidas y jocosas de distintos personajes históricos: Cicerón, Augusto, Julia (hija de Augusto) y otros. Y dice en Sat. II 1, 14: iocos enim hoc genus ueteres nostri dicta dicebant.

El pasaje en cuestión, Sat. II 4, 11 es una de las muchas anécdotas que el autor pone en boca de Augusto, pero es extraño que ni Suetonio, ni ninguna de las posibles fuentes del autor de las Saturnales, mencione dicha narración. Por otra parte, dada la política de Augusto con los judíos, especialmente con la familia de Herodes, parece evidente, como antes decía, que Macrobio recogiera el hecho de la lectura del Evangelio de Mateo y la utilizara de una manera indirecta por medio de Augusto. No hay que perder de vista que nuestro autor, en toda su obra, ignora sistemáticamente a los cristianos; por ello no es extraño que se valiera de una ficción para comentar un hecho que debió llamar su atención poderosamente.

\section{Consolación Granados Fernández}

